\title{
Study on Science and Technology Innovation New Measures in Developed Countries and Experience Reference in China
}

\author{
Wang Xiaodi \\ International Information Research Department \\ Beijing Institute of Science and Technology \\ Beijing, China \\ E-mail: wangxd@bjstinfo.com.cn
}

\begin{abstract}
In 2016, although there have been a series of major events in developed countries, developed countries science and technology innovation have continued to increase investment in fields of science research, research scope expanding, establishment of a new science research goal to ensure competitive position capability in the world stage. This paper analyzed main fields of science and technology innovation implementation in US, new research promotion policy in UK, and government and private enterprises investment cooperation committee establishment in Japan. The authors studied experience and put forward suggestions for perfecting China's science and technology innovation system, expanding research fields and promoting innovation-oriented country.
\end{abstract}

Keywords-Science and technology innovation; Innovation system; Strategy; Policy measures

\section{INTRODUCTION}

Science and technology innovation is national development fundamental motive force, and also it is primary productive force and national development factors. Nowadays, many countries in the world, especially developed countries emphasize technology innovation development. Governments have ensured and promoted science and technology innovation activities implementation by formulating a large number of science and technology innovation policy, strategy construction, and science technology innovation environment.

Science research based technological innovation has become the most significant driving force for national economic progress. Furthermore, it is racing control key of global economic competition commanding elevation point. Building and improving national science and technology innovation system has become top priority in recent years; governments have introduced corresponding innovation policies and delivery plans, government agencies innovation establishment, improving enterprise technical capability and strengthening international science and technology cooperation. It is of great practical significance to fully understand and study these experiences as purpose to improving China's science and technology innovation system, promoting innovation-oriented country and expanding research fields.

\section{FOREIGN SCIENCE AND TECHNOLOGY INNOVATION NEW FUTURE STRATEGY DEVELOPMENT}

\section{A. The United States}

In October 13, 2016, at United States Pittsburgh, the "White House Summit Conference" has been convened and based on "2015 Strategy for American Innovation". The conference focuses on individual, regional, national, global and space exploration, 5 technological frontiers, challenges for science, technology, and innovation in the next 50 years. The aim of conference is to promote US science and technology development and maintain the most innovative nation position. It has concluded main fields for US future development science, technology and innovation in following aspects:

(1) Individual: US government will increase input for the National Institutes of health in the "The Human Brain Project (HBP)", with an additional investment of $\$ 70$ million. The project has referred to the full range of cognition on through gene, US government will provide $\$ 300$ million budget to support scientists and doctors will diagnose and treat neurological diseases. By the end of 2016, US government had invested $\$ 150$ million for the National Institutes of Health (NIH) HBP, and the number of related projects doubled as compared with the previous year. US government and enterprise has invested $\$ 1.5$ billion since HBP was launched in 2013. At the same time, 4 regional medical institutions in US have joined the Obama administration's life sciences new project - "Precision Medicine Initiative" in 2015, and NIH will provide $\$ 16$ million in research funding for science research institutions.

(2) Regional: US Department of Transportation contributed nearly $\$ 65$ million to develop smart city research projects to help solve traffic congestion, urban security and other issues. Moreover, US enterprises will also invest \$100 million research funding to promote smart city development. In 2016, US government budget has $\$ 30$ million to invest in smart cities in new research and deployment of smart city facilities. There will be a growing number of community managers, data scientists, technicians and businesses collaboration to establish "smart city". 
(3) National: Artificial intelligence (AI) report has issued and listed facing problems and challenges of AI development, including social and economic development, employment and social security issues. US Department of transportation has issued autonomous pilotless vehicle and unmanned aerial vehicle (UAV) relevant specific management policies, insurance systems and measures. In 2016, US government finance doubling investment in automotive technology research and improved autonomous vehicle safety standards and performance. Breakthroughs in sensor, computer and data science have led to vehicle communications and cutting-edge proprietary technologies into commercial use.

(4) Global: in response to global climate change, US will continue to finance clean energy innovation and climate change solutions. From 2009 to 2015 years, US wind and solar power generation has increased by 20 times, Federal government has decided to improve energy utilization, to enhance US energy security, and maintain energy production capacity increasing.

(5) Space exploration: US government has cooperated with private enterprises to develop space stations to help achieve manned landing of Mars in 2030. In addition, US NASA will invest $\$ 50$ million to develop "Small Satellite Revolution" technology to promote network technology development. In 2016, US government financing budget of $\$ 1.2$ billion has spent on NASA's commercial space program and \$725 million for NASA Space Technology Mission Council, such as protecting astronauts from space radiation, advanced propulsion systems and space survival research technology (energy production, oxygen manufacturing and water production) [1].

\section{B. United Kingdom}

By November 21, 2016, the UK Prime Minister Theresa Mary May announced new research and development policy for science and technology innovation in UK which formulated a long-term industrial development strategy. As follows:

(1) For UK enterprises to maintain a high level development and research capabilities in the world, by 2020 , UK government had spent about $£ 2$ billion found a year on research and development of new technologies. UK government has become the best European country which engaged in innovative activities, patent application and entrepreneurship and enterprise development environment, to help universities and enterprises cooperation. Not only to make research findings commercialization, but also make current and future research to adapting a competitive global market.

For this purpose, UK government has adopted a series of measures to encourage enterprises to invest in new research and development activities, and actively take advantage of new research achievement. By 4 university-enterprise zones (Bristol, Brad Ford, Liverpool and Nottingham) investment, there will create 1000 jobs in small high-tech enterprises in 2020; technology innovation center will be established to ensure a favorable environment for researchers and innovators of emerging technology commercialization.
(2) A special research foundation "Industry Strategy Challenge Fund" will be founded to support UK's dominant technologies (such as robotics and biotechnology) for industrial development transformation into business models. The foundation provides funding for dominant technology development and research projects, and a long-term supports for UK's fundamental upgrading of existing research and development capabilities.UK Research and Innovation (UKRI) has responsibility for Monitoring industry strategic challenge fund. This foundation has provided support in science research ability, economic value technology, implementation technique and commercialized development (including robotics, artificial intelligence, industrial biotechnology, medical technology, satellite, advanced manufacturing technology and others).

(3) In order to ensure UK science and technology competitiveness in the world, UK government will provide a preferential tax system for science researchers, innovators and technical investors. In 2010, UK government has taken to reduce corporate taxes, tax relief measures by increasing research and development activities in enterprises tax reform, is one of the few countries to take the lead in competitive corporate tax system implementation. As a result, UK Treasury has improved policy measure roles and better effects in order to promote UK's continued innovation development [2].

\section{Japan}

Japan's government attaches great importance to science research and innovation cooperation in public and private interests, this cooperation mode can build a new mechanism of technology innovation investment for technology and product research development promoting, knowledge and technical transferring, conception and technology commercialization application, so as to advance overall science and technology innovation development in Japan. For this purpose, the Japanese Prime Minister decided to found a government and private enterprises investment research committee to advance science and technology innovation and development.

\section{1) Public-Private Partnerships Research Committee} establishment

(1) According to "Japan Comprehensive Strategy of Science and Technology Innovation" order, Japan Comprehensive Science and Technology Innovation Conference was responsible for promoting science and technology innovation development.

(2) The committee has been aimed at investigation and research in research and development by "Cooperative Investment Initiative Science and Technology Innovation of Public-Private Partnerships Expansion".

(3) On the basis of "Japan Comprehensive Strategy of Science and Technology Innovation" order, Japan Comprehensive Science and Technology Innovation Conference would submit differing comment, suggestion and concrete implementation plan to the Japanese Prime minister through investigation research outcome. 


\section{2) Japan Comprehensive Science and Technology} Innovation Conference

In May 2014, Japan government reorganized the top science and technology decision-making body and Comprehensive Science and Technology Conference of Cabinet Office into "Comprehensive Science and Technology Innovation Conference". "Science and Technology Innovation Comprehensive Strategy 2014 (Draft)" issued and highlighted Comprehensive Science and Technology Innovation Conference as scientific research top management institution played the strongest promoting role so far in terms of authority and budget. Furthermore, it has implemented proactively and flexibility in cross sector guidance policy. Strengthening cooperation and innovation with relevant leading departments (Japan's economic regeneration department and regulatory reform conference) and headquarters organization for science and technology innovation, government of Japan could eliminate departmental fragmentation, enhance government academic cooperation, and promote basic research industrialization transformation [3].

Japan various innovation programs has developed from industry and education cooperation to "Three triple helix Industries, Universities and Government Cooperation" structure. In the new cooperation mechanism type, government has allowed full play to strategic guidance function, while universities and research institutes provided advanced technology and research overcomes, and enterprises emphasized in science research achievements marketization. Technology transformation and technological forecasting PPP (Public-Private-Partnership, PPP) model have tightly developed in "Industries, Universities and Government Cooperation" mode. Government of Japan has promoted science and technology and economy development through cooperation with enterprises and research institutions. It has improved technology innovation and technology transfer efficiency; on the other hand, it has effectively optimized scientific and technological resources allocation [4].

\section{FOREIGN SCIENCE AND TECHNOLOGY INNOVATION SYSTEM CONSTRUCTION MEASURES AND ENLIGHTENMENTS}

\section{A. Technological forecasting is an effective tool for making important science and technology strategy}

Launching science and technology forecast and promulgating guidance of science and technology strategy planning is an effective basis for governments to grasp science frontier and formulate specific research projects. US government has attached importance to prospective research and development. Through key technologies plan to identify key areas of science and technology development, it has created favorable conditions in many fields [5].

Since 1970s, Japan has organized and implemented a number of technological forecasting activities by Science and Technology Department, and formed Industrial technology development policies and plans for government and enterprise, thus it has enhanced national competitiveness and level; in the 90s of the last century, European countries such as UK, France and Germany have also strengthened science and technology forecasting. In accordance with forecast results it has identified a cross century science and technology development fields and dominant project plan [6].

\section{B. Innovation Management Specialization}

At present, China has not yet established government innovation agency. The science and technology innovation policy, such as enterprise innovation preferential policy, it has been implemented by cooperate with science and technology, finance and taxation departments to ensure effective communication and coordination. From experience abroad, government innovating agency establishment would help to integrate innovation resources, promote national innovation system coordination and push forward innovation activities. In addition, in view of the dominant position of the enterprise in the innovation system, China may consider setting up special organizations to promote enterprises technological innovation, such as chief science officer and the chief science adviser office [7].

\section{Improving fiscal and taxation policies, promoting science and technology innovation}

Fiscal incentives for corporate R \& D include: pretax deductions or tax credits, tax incentives tracing, emergency depreciation, and extraction technique reserves.

At present, China's current science and technology tax law has a difficult taxation regulatory. Therefore, from a long-term review, China's government should formulate and furtherance comprehensive high-tech industry development statute. At present, the specific tax preferential policies were promulgated and summarized by the State Council, Ministry of Finance and State Taxation Administration. Science and technology tax policy implementation has required separate legislation, and objectives, principles, methods and specific measures, scope, approval procedures has defined as needed. Furthermore, we should reinforce and enhance standardization, transparency and integrity of science and technology tax preferences.

Science and technology tax preferences should be focused in high-tech enterprises investment risk in compensation and reduction. At present, tax incentives are mainly applied to hightech products production and marketing, which are gradually converted to science and technology developing compensation and semiplant test phase, also enhanced integration effect of science and technology tax policy.

\section{Public-Private-Partnership (PPP) Mode in science and technology innovation}

The Public-Private-Partnership (PPP) mode in science and technology innovation has realized social benefits maximization, also ensured profitable enterprises and social capital. As a result, it is the best model for public project management.

When PPP mode is mature, we can continue to carry out large-scale science and technology innovation programs by using inter regional PPP mode. The government should focus on cutting-edge technology in key fields. 
In recent years, the number of small and medium-sized enterprises (SMEs) in China is increasing, has become China's largest and dynamic innovation group. The innovation investment of SMEs has increased rapidly, accelerated new technology and products output, also become China's science and technology innovation main force and sustained national economy development important foundation.

In the field of science and technology PPP mode, if China's government can able to mobilize the widespread participation of SMEs, will be able to give full play to the role of endogenous innovation system of small and medium-sized enterprises, to help small and medium-sized enterprises to continuously improve the ability of technological innovation, so as to enhance China's science and technology innovation standard, fasten technology transform into productivity, promote technology innovation become main driving force for China's economic growth [8].

\section{CONCLUSION}

Science and technology innovation is an important force to promote national development forward. Nowadays, China has faced pressure of economic development mode transformation economic restructuring. Promoting science and technology innovation can furtherance economic development. Firstly, China government can draw lessons from US science and technology innovation method, increase urban agricultural science and technology investment, realize energy conservation and environmental protection. Secondly, we can learn feasible experience from UK and European to implement long-term science research activities to achieve economic growth and overall development. Finally, While the Asian country, Japan had formulated long term science planning and science and technology diplomacy strategy. It has advancing facilitation effect in promoting science and technology progress and economic development, but also a development mode that we can be used for reference. By drawing on the experience of developed countries, we hope it can effectively establish science and technology innovation policy in China.

\section{REFERENCES}

[1] White House Government website: https://www.whitehouse.gov/thepress-office/2016/10/13/fact-sheet-harnessing-possibilities-sciencetechnology-and-innovation.

[2] UK Prime Minister website: https://www.gov.uk/government/news/pmannounces-a-2-billion-investment-in-research-and-development.

[3] Japan Comprehensive Strategy of Science and Technology Innovation Website: http://www8.cao.go.jp/cstp/tyousakai/target/1kai/1 kai.html.

[4] Shijuan Liang, Zilong Zhang, Shouqing Wang. A comparative study of government management of PPP projects in China, UK, Japan and Korea [J]. Project Management Technology, 2013, 11(5):17-18.

[5] Business summary - Enterprise-University cooperation technology transformation operation. Optimization support program for research results A-STEP [EB/OL].[2015-12-13]. http://www.jst.go.jp/astep/outline/index.html\#TOP.

[6] Wei Xue, Mingxi Zhang, Rong Guo. New Supply Model of Quasi Public Technology Products [R]. High-Technology \& Industrialization. 2011(6).

[7] Yan Liu. US science and technology innovation system Enlightenment to China innovative oriented construction [D]. Bohai University, 2013.

[8] Shaohuan Li. The future Chinese science and technology innovation and management strategy [J]. Scientific Management Research, 2013(2): 5-7. 